\title{
Biological and Immunological Characterization of Human Luteinizing Hormone Discharged by the Stimulation of Synthetic Luteinizing Hormone-Releasing Hormone (LH-RH) in Normal and Anovulatory Women
}

\author{
Hiroshi SUGINAMI, Hisashi MASAOKA, Yukio KOIZUMI, \\ Mariko YANO, Katsuyuki HAMADA and Akira NAKAJIMA \\ Department of Obstetrics and Gynecology School of Medicine, \\ Ehime University Shigenobu, Ehime 791-02
}

\begin{abstract}
Plasma samples were obtained by repeated venopunctures immediately before, and at $15,30,60,120$ and $180 \mathrm{~min}$ after intravenous bolus administration of $100 \mu \mathrm{g}$ synthetic LH-RH in normal and various anovulatory women. Plasma hLH levels were determind by an in vitro bioassay and a radioimmunoassay with improved reagents. The LH-RH stimulation induced an abrupt elevation of both biological and immunological hLH activities in normal and anovulatory women, although the responsiveness to LH-RH differed from case to case. Both elevated biological and immunological hLH activities decreased gradually with a half disappearance time of $122.4 \pm 27.9 \mathrm{~min}$ and $112.5 \pm 25.4 \mathrm{~min}$, respectively (Mean \pm S.D.). A transient and significant depression in the ratio of biological to immunological hLH activities (B/I ratio) was observed at $15 \mathrm{~min}$ after the $\mathrm{LH}-\mathrm{RH}$ administration in normal subjects. This depression is attributable to the cross-contamination of an increased amount of hLH subunits induced by LH-RH stimulation. The B/I ratios were significantly elevated throughout the investigation period in the anovulatory patients when compared with those in the normal subjects. This elevation appears to indicate the increased discharge of special type(s) of hLH subpopulations of high biological potency in the anovulatory cases.
\end{abstract}

A decapeptide with a potent action on the release of pituitary gonadotropins (luteinizing hormone-releasing hormone; LH-RH) has been synthesized and widely applied for various clinical and research purposes. It is evident now that the administration of synthetic LH-RH evokes a rapid and significant discharge of human luteinizing hormone (hLH) in human adults of both sexes.

It is rather well known that the $\mathrm{LH}$ is not a hormone of homology but consists of multiple subpopulations separable by isoelectrofocusing techniques (Robertson \& Diczfalusy 1977; Wakabayashi, 1977; Ro-

Received November 13, 1981. bertson et al., 1977; Van Damme et al., 1977; Strollo et al., 1981; Yano et al., 1981; Zaidi et al., 1982). Stimulation by LH-RH causes relative changes in the amount of hLH subpopulations discharged among subjects investigated; i.e. the increase in more acidic or neutral fractions was observed when postmenopausal plasma was compared with midcycle plasma (Strollo et al., 1981) and when luteal plasma was compared with midcycle plasma (Yano et al., 1981). Each hLH subpopulation appears to have its own biological and immunological properties (Yano et al., 1981).

The purpose of the present study was to characterize the biological and immunological properties of $\mathrm{hLH}$ discharged by 
LH-RH stimulation in normal and various anovulatory women.

\section{Materials and Methods}

\section{Clinical material}

Seven adult female volunteers participated in the present study. All of them were of fertile age (21$27 \mathrm{yr}$ ) with a history of regular cycles and had no medication. The LH-RH administration and blood sampling was performed in the follicular phase (cycle date of 6-10).

21 anovulatory patients were also investigated. 7 of these 21 patients were diagnosed as polycystic ovarv syndrome (PCO) retrospectively with laparotomy and/or laparoscopic findings. The remaining 14 patients were classified into 3 groups in terms of hLH levels before LH-RH stimulation, i.e. hypergonadotropic (3 cases), normogonadotropic (9 cases), and hypogonadotropic ( 2 cases). The data obtained from 3 hypergonadotropic and 2 hypogonadotropic patients were discarded from statistical analysis owing to the paucity of the number.

To these normal volunteers and patients, $100 \mu \mathrm{g}$ synthetic LH-RH (Tanabe Pharmaceutical Co., Osaka, Japan) was administered intravenously at 9:00 AM. Blood was withdrawn by repeated venoduncture immediately before, and at $15,30,60,120$, and 180 min after the LH-RH administration. Plasma samples thus obtained were stored frozen at $-70^{\circ} \mathrm{C}$ in aliquots until being assayed.

A plasma pool from multiple postmenopausal women was prepared for a quality control of the assays.

\section{In vitro bioassay for $h L H$}

The in vitro bioassay for hLH employed (Suginami et al., 1981b) was a modification of that reported by Van Damme et al., (1974). The method is based on the testosterone production by dispersed mouse testis interstitial cell preparations which is dependent on the doses of hLH. The method has been validated in its use on human female plasma (Romani et al., 1977; Suginami et al., $1981 \mathrm{a}, \mathrm{b}$ ) and also on male plasma (Rajalakshmi et al., 1979; Bartfai et al., 1979). The mice used as the source of testis interstitial cells were derived from the C57 black strain aged 7 to 9 weeks (Suginami et al., 1981b). All the samples were pre-treated with an equal volume of $0.5 \%$ Norit A charcoal for $30 \mathrm{~min}$ at $4^{\circ} \mathrm{C}$ with occasional agitation prior to centrifugation in order to remove substances of low molecular weight including various steroidal precursors (Rajalakshmi et al., 1979). This modification was introduced in the present study as a precautionary step rather than out of necessity. The standard preparation employed was the human pituitary LH 1st IRP for immunoassay (Code No. 68/40), supplied by the National Institute for Biological Standards and Control, London, England. The sensitivity of the assay was $6.25-12.5 \mu \mathrm{IU} /$ tube. The index of precision ( $\lambda$ ) was $0.02-0.05$. The quality control plasma (the pooled postmenopausal plasma) was measured by this method and found to be $88.3 \pm 5.8$ $\mathrm{mIU} / \mathrm{ml}($ Mean \pm S.D.; $\mathrm{n}=11)$.

\section{$h L H$ radioimmunoassay}

An equilibrium radicimmunoassay (RIA) method was employed in the assessment of immunological activities of hLH with improved reagents (Suginami et al., 1978, 1981a). An anti-hLH serum and a highly purified human pituitary LH preparation (LER 960) were provided for the present study by the National Pituitary Agency, NIH, Bethesda, Maryland, USA. The LER 960 preparation was iodinated with a lactoperoxidase method (Suginami et al., 1981a). The iodinated products were purified by gel filtration on Ultrogel AcA 54 (LKB Produkter AB, Bromma, Sweden) as described by Suginami et al. (1978). The incubation of sample plasma or the $68 / 40$ preparation $(200 \mu 1)$ for 3 days at room temperature with iodinated hLH $(100 \mu 1 ; c a .20,000 \mathrm{dpm})$ and anti-hLH serum $(100 \mu \mathrm{l}$; diluted 1:8000) was terminated by the double antibody procedure. The sensitivity of the assay was $0.625-1.25 \mathrm{mIU} /$ tube. The index of precision $(\lambda)$ was $0.02-0.05$. The same quality control plasma as was also used in the in vitro bioassay was measured by this method and found to be $67.9 \pm 5.3 \mathrm{mIU} / \mathrm{ml}$ (Mean \pm S.D.; $\mathrm{n}=7$ ).

\section{Assay design}

All the assay tubes were randomized in order to eliminate systematic errors. A multiple $2+2$ parallel line assay design (Finney 1978) was employed with 2 dose levels and 3 replicates per dose level in the assessment of the hLH activities of the sample plasma after the estimation of parallelism against the linearlized standard response line in both the bioassay and RIA. A logit log dose transformation was employed for linearization in both assays (Robertson et al., 1978; Suginami et al., 1981a, b). Samples showing non-parallelism were omitted from further analyses, although most of them showed statistical parallelism in both assays.

The half disappearance time $\left(t_{1 / 2}\right)$ of $h L H$ from circulation was calculated by the linear regression lines with the estimates at $30,60,120$ and $180 \mathrm{~min}$ after the LH-RH administration after logarithmic transformation. Some of the statistical methods, such as two way analysis of variance, Student's $t$ test, Welch's $t$-test, etc., were employed for the evaluation of the results obtained. 


\section{Results}

\section{Normal subjects}

Plasma levels of biological and immunological hLH activities before the LH-RH administration (control values) were 14.7 \pm $5.6 \mathrm{mIU} / \mathrm{ml}$ (Mean \pm S.D.) and $14.1 \pm 4.7$ $\mathrm{mIU} / \mathrm{ml}$, respectively. Intravenous administration of $100 \mu \mathrm{g}$ synthetic LH-RH evoked an abrupt elevation of plasma levels of both biological and immunological hLH activities, reaching $80.3 \pm 35.8 \mathrm{mIU} / \mathrm{ml}$ and 72.2 $28.3 \mathrm{mIU} / \mathrm{ml}$, respectively, at $30 \mathrm{~min}$ after the LH-RH administration (Table 1). As time passed the elevated plasma hLH levels declined gradually (Tabel 1) and linearly when the estimates were plotted on a semilogarithmic scale. The $t_{1 / 2}$ 's of biological and immunological hLH activities were $125.8 \pm 21.7 \mathrm{~min}$ and $106.2 \pm 19.7 \mathrm{~min}$, respectively, showing no statistical significance (Table 3). The ratios of biological to im- munological hLH activities (B/I ratios) were maintained above unity throughout most of the treatment period, although a significant depression was observed at $15 \mathrm{~min}$ after the LH-RH administration $(0.94 \pm 0.09 ; \mathrm{p}<0.05)$ (Table 2).

Table 3. The half disappearance time of biological and immunological activities of hLH discharged by the intravenous administration of $100 \mu \mathrm{g}$ synthetic LH-RH in normal follicular phase $(n=7)$, PCO $(n=7)$ and normogonadotropic anovulatory patients $(\mathrm{n}=9)$. Means and standard deviations are presented.

\begin{tabular}{lcc}
\hline \hline & \multicolumn{2}{c}{ Half disappearance time (min) } \\
\hline Bioactivity & Immunoactivity \\
\hline PCO & $120.8 \pm 21.7$ & $106.2 \pm 19.7$ \\
Anov. & $124.5 \pm 22.3$ & $112.8 \pm 21.6$ \\
\hline Total & $123.6 \pm 30.5$ & $115.1 \pm 28.1$ \\
\hline
\end{tabular}

The half disappearance time was calculated by the linear regression lines with the estimates at 30,60 , 120 and $180 \mathrm{~min}$ after the LH-RH administration.

Table 1. Plasma hLH levels before and after the LH-RH stimulation in normal follicular phase $(n=7)$, PCO $(n=7)$ and normogonadotropic anovulatory patients $(n=9)$ as measured by the bioassay and RIA. Means and standard deviations are presented.

\begin{tabular}{|c|c|c|c|c|c|c|c|}
\hline & & \multicolumn{6}{|c|}{ Time after LH-RH administration (min) } \\
\hline & & 0 & 15 & 30 & 60 & 120 & 180 \\
\hline \multirow{3}{*}{ Bioassay } & Normal & $14.7 \pm 5.6$ & $55.5 \pm 25.9$ & $80.3 \pm 35.8$ & $69.3 \pm 32.0$ & $53.7 \pm 20.6$ & $40.2 \pm 11.9$ \\
\hline & $\mathrm{PCO}$ & $52.5 \pm 11.3$ & $189.8 \pm 30.5$ & $242.6 \pm 57.2$ & $225.2 \pm 44.2$ & $155.4 \pm 19.4$ & $123.6 \pm 17.7$ \\
\hline & Anov. & $23.3 \pm 13.5$ & $73.3 \pm 25.3$ & $112.0 \pm 52.9$ & $100.7 \pm 46.9$ & $71.0 \pm 31.6$ & $50.9 \pm 27.0$ \\
\hline \multirow{3}{*}{ RIA } & Normal & $14.1 \pm 4.7$ & $60.3 \pm 28.5$ & $72.2 \pm 28.3$ & $60.3 \pm 24.8$ & $47.7 \pm 18.9$ & $36.9 \pm 9.6$ \\
\hline & $\mathrm{PCO}$ & $36.8 \pm 6.7$ & $140.8 \pm 37.8$ & $183.9 \pm 50.4$ & $145.8 \pm 42.6$ & $98.6 \pm 29.9$ & $82.6 \pm 21.5$ \\
\hline & Anov. & $22.6 \pm 7.2$ & $67.0 \pm 25.1$ & $90.0 \pm 40.6$ & $70.6 \pm 30.1$ & $48.3 \pm 15.4$ & $37.5 \pm 9.9$ \\
\hline
\end{tabular}

Results are expressed in terms of $\mathrm{mIU} / \mathrm{ml}$ of the $68 / 40$ standard preparation.

Table 2. The ratios of biological to immunological activities of hLH (B/I ratios) before and after the LH-RH stimulation in normal follicular phase $(n=7)$, PCO $(n=7)$ and normogonadotropic anovulatory patients $(n=9)$. Means and standard deviations are presented.

\begin{tabular}{|c|c|c|c|c|c|c|}
\hline & \multicolumn{6}{|c|}{ Time after LH-RH administration (min) } \\
\hline & 0 & 15 & 30 & 60 & 120 & 180 \\
\hline Normal & $1.04 \pm 0.07$ & $0.94 \pm 0.09 \dagger$ & $1.09 \pm 0.13$ & $1.13 \pm 0.14$ & $1.16 \pm 0.20$ & $1.23 \pm 0.23$ \\
\hline PCO & $1.44 \pm 0.25^{* *}$ & $1.41 \pm 0.33^{*}$ & $1.36 \pm 0.29$ & $1.59 \pm 0.24^{* *}$ & $1.64 \pm 0.41^{*}$ & $1.55 \pm 0.28$ \\
\hline Anov. & $1.24 \pm 0.24^{*}$ & $1.18 \pm 0.28^{*}$ & $1.34 \pm 0.36$ & $1.51 \pm 0.37^{*}$ & $1.53 \pm 0.39 *$ & $1.39 \pm 0.36$ \\
\hline
\end{tabular}

* Statistical significance against the corresponding values obtained in the normal subjects $(\mathrm{p}<0.05)$.

** Statistical significance against the corresponding values obtained in the normal subjects $(\mathrm{p}<0.01)$.

$\dagger$ Statistical significance against the B/I ratios before the LH-RH stimulation $(\mathrm{p}<0.05)$. 


\section{PCO cases}

The control values for both biological and immunological hLH activities for these PCO patients $(52.5 \pm 11.3 \mathrm{mIU} / \mathrm{ml}$ and 36.8 $\pm 6.7 \mathrm{mIU} / \mathrm{ml}$, respectively) were significantly higher than those for normal subjects (Table 1). The LH-RH stimulation induced also a prominent discharge of $\mathrm{hLH}$, although the responsiveness to injected synthetic LH-RH (as reflected by the net increase of hLH activities) was much enhanced when compared to that in the normal subjects (Table 1). The $t_{1 / 2}$ 's of biological and immunological hLH activities in these PCO patients ware $124.5 \pm 22.3 \mathrm{~min}$ and $112.8 \pm$ $21.6 \mathrm{~min}$, respectively. These two values were not significantly different from each other or from those in the normal subjects (Table 3). The $B / I$ ratios in these patients were elevated sigeificantly throughout the investigation period in comparison with the corresponding values in the normal subjects ( $\mathrm{p}<0.01$ at Time 0 and 60 , and $\mathrm{p}<0.05$ at Time 15 and 120) (Table 2).

\section{Normogonadotropic anovulatory cases}

The responsiveness, in terms of $\mathrm{hLH}$ discharge from the pituitary, to injected synthetic LH-RH in these patients was similar to that in the normal subjects (Table 1). The $t_{1 / 2}$ 's of elevated biological and immunological hLH activities were comparable to each other and not different from those in the normal subjects (Table 3). However, the $B / I$ ratios in these patients were elevated significantly throughout the investigation period when compared with the corresponding $B / I$ ratios in the normal subjects $(\mathrm{p}<0.05$ at Time $0,15,60$ and 120) (Table 2),

\section{Discussion}

A significant elevation of plasma $\mathrm{hLH}$ levels was detected by both the in vitro bioassay and RIA employed in the present study when $100 \mu \mathrm{g}$ synthetic LH-RH was administered intravenously to normal and various anovulatory women. These two assays provided comparable data to those reported by many investigators as far as the profile of hLH levels is concerned.

The elevated plasma hLH levels decreased gradually and linearly when the estimates obtained were plotted on a semilogarithmic scale. The $t_{1 / 2}$ 's of both biological and immunological hLH activities in the anovulatory patients were not different from those in the normal subjects. These $t_{1 / 2}$ values are comparable to those obtained on naturally occurring hLH pulses in the normal menstrual cycle (Santen \& Bardin, 1973; Suginami et al., 1982). Furthermore, they are in close agreement with the results in the literature (Schalch et al., 1968; Kohler et al., 1968; Nankin \& Troen, 1972; Yen et al., 1972) and significantly longer than the rapid half life of endogenous hLH after complete hypophysectomy (Yen et al., 1968). This difference could be attributed to the residual action of LH-RH upon intact pituitary.

A significant and transient depression in $\mathrm{B} / \mathrm{I}$ ratios soon after the LH-RH administration was observed in the normal subjects in the present study. This depression is attributable to the cross-contamination of an increased amount of hLH subunits, positive immunological activity and lack of biological activity in plasma under the influence of the administered synthetic LHRH (Benveniste et al., 1973, 1975; Hagen \& McNeilly, 1975a, b). Most of the hLH subunits secreted by LH-RH stimulation are likely to disappear from circulation in a short time course (Braunstein et al., 1972; Benveniste et al., 1975). Because of the rapid disappearance of $\mathrm{hLH}$ subunits, the depressed $\mathrm{B} / \mathrm{I}$ ratio could not have lasted long and was recovered soon. In contrast with the results obtained in the present study, the absence of the depression of $\mathrm{B} / \mathrm{I}$ ratios after LH-RH stimulation was reported 
in normal subjects (Dufau et al., 1976). This disagreement seems to be owing to the methodological differences or to the paucity of the number of subjects examined in their study.

One of the most important items of evidence obtained in the present study is that the $B / I$ ratios in the anovulatory patients were significantly elevated throughout the investigation period in comparison with those in the normal subjects. This is interpreted as indicating that the special type(s) of hLH subpopulations of relatively high biological potency is secreted more in these anovulatory patients than in the normal subjects. It is now quite well known that the LH is not an homologous hormone but consists of multiple subpopulations separable by isoelectrofocusing techniques (Robertson \& Diczfalusy, 1977; Wakabayashi 1977; Robertson et al., 1977; Van Damme et al., 1977; Strollo et al., 1981; Yano et al., 1981 ; Zaidi et al., 1982). When pituitary homogenates, plasma or urinary samples are fractionated by isoelectrofocusing techniques, the majority of $\mathrm{LH}$ activity migrates to the alkaline region. Recent investigations demonstrated relative changes in the amount of hLH subpopulations under various conditions. For instance, the increase in acidic or neutral fractions was observed when postmenopausal plasma was compared with midcycle plasma (Strollo et al., 1981) and when female plasma in the luteal phase was compared with midcycle plasma (Yano et al., 1981). Each hLH subpopulation appears to possess its own biological and immunological properties; i.e. the $\mathrm{B} / \mathrm{I}$ ratio of acidic $\mathrm{hLH}$ is significantly and markedly decreased when compared with that of alkaline hLH (Robertson \& Diczfalusy, 1977 ; Robertson et al., 1977; Yano et al., 1981). Identification of the hLH subpopulation(s) which caused the elevation of $B / I$ ratios in the anovulatory patients in the present study is to be performed in future.

\section{Acknowledgements}

The hLH standard preparation (68/40) was a gift from the National Institute for Biological Standards and Control, London, England. The anti-hLH serum and the highly purified human pituitary LH preparation (LER 960) were supplied by the National Pituitary Agency, NIH, Bethesda, Maryland, USA. The anti-testosterone-3-oxime-BSA serum was provided by the Teikoku Hormone Co., Tokyo, Japan, and was used in the detection of testosterone produced by the dispersed mouse testis interstitial cells in the in vitro bioassay employed.

This work was supported in part by Grant-ir-Aid for Scientific Research No. 448315 from the Japanese Ministry of Education.

\section{References}

Bartfai, G., D. M. Robertson and E. Diczfalusy (1979). Biologically active luteinizing hormone (LH) in plasma: IV. Comparison with immunologically active LH in plasma of men. Acta Endocrinol. (Kbh.) 90, 599-608.

Benveniste, R., J. Bell, J. Koeppel and D. Rabinowitz (1973). Alpha chain of glycoproteins: Presence in human serum after thyroid stimulating hormone releasing hormone. J. Clin. Endocrinol. Metab. 37, 822-825.

Benveniste, R., L. A. Frohman, J. Bell, I. Spitz and D. Rabinowitz (1975). Alpha subunit of glycoprotein hormone: Presence in peripheral serum after LHRH. Eur. J. Clin. Invest. 5, 123-131.

Braunstein, G. D., J. L. Vaitukaitis and G. T. Ross (1972). The in vitro behavior of human chorionic gonadotropin after dissociation into subunits. Endocrinology 91, 1030-1036.

Dufau, M. L., I. Z. Beitins, J. W. McArthur and K. J. Catt (1976). Effects of luteinizing hormone releasing hormone (LHRH) upon bioactive and immunoreactive serum LH levels in normal subjects. J. Clin. Endocrinol. Metab. 43, 658-667.

Finney, D. J. (1978). Statistical Method in Biological Assay (3rd edition). Charles Griffin Co., London, England.

Hagen, C., and A. S. McNeilly (1975a). The specificity and application of a radioimuunoassay for the $\alpha$-subunit of luteinizing hormone in man. Acta Endocrinol. (Kbh.) 78, 664-674.

Hagen, C., and A. S. McNeilly (1975b). Changes in circulating levels of LH, FSH, LH $\beta$ - and $\alpha$ subunit after gonadotropin-releasing hormone, and of TSH, $\mathrm{LH} \beta$ - and $\alpha$-subunit after thyrotropinreleasing hormone. J. Clin. Endocrinol. Metab. 41, 466-470. 
Kohler, P. O., G. T. Ross and W. D. Odell (1968). Metabolic clearance and production rates of human luteinizing hormone in pre- and postmenopausal women. J. Clin. Invest. 47, 38-47.

Nankin, H. R., and P. Troen (1972). Overnight patterns of serum luteinizing hormone in normal men. Acta Endocrinol. (Kbh.) 35, 705-710.

Rajalakshmi, M., D. M. Robertson, S. K. Choi and E. Diczfalusy (1979). Biologically active luteinizing hormone (LH) in plasma: III. Validation of the in vitro bioassay when applied to male plasma and the possible role of steroidal precursors. Acta Endocrinol. (Kbh.) 90, 585-598.

Robertson, D. M., and E. Diczfalusy (1977). Biological and immunological characterization of human luteinizing hormone: II. A comparison of the immunological and biological activities of pituitary extracts after electrofocusing using different standard preparations. Mol. Cell. Endocrinol. 9, 57-67.

Robertson, D. M., M. P. Van Damme and E. Diczfalusy (1977). Biological and immunological characterization of human luteinizing hormone: I. Biological profiles in pituitary and plasma samples after electrofocusing. Mol. Cel. Endocrinol. 9, 45-56.

Robertson, D. M., B. Froysa and E. Diczfalusy (1978). Biological and immunological characterization of human luteinizing hormone: IV. Biological and immunological profiles of two international reference preparations after electrofocusing. Mol. Cell. Endocrinol. 11, 91-103.

Romani, P., D. M. Robertson and E. Diczfalusy (1977). Biologically active luteinizing hormone (LH) in plasma: II. Comparison with immunologically active LH levels throughout the human menstrual cycle. Acta Endocrinol. (Kbh.) 84, 697712.

Santen, R. J., and C. W. Bardin (1973). Episodic luteinizing hormone secretion in man. Pulse analysis, clinical interpretation, physiologic mechanisms. J. Clin. Invest. 52, 2671-2628.

Schalch, D. S., A. F. Parlow, R. C. Boon and S. Reichlin (1968). Measurement of human luteinizing hormone in plasma by radioimmunoassay. $J$. Clin. Invest. 47, 665-678.

Strollo, F., J. Harlin, H. Hernandez-Montes, D. M. Robertson, A. A. Zaidi and E. Diczfalusy (1981). Qualitative and quantitative differences in the isoelectrofocusing profile of biologically active lutropin in the blood of normally menstruating and postmenopausal women. Acta Endocrinol. (Kbh.) 97, $166-175$.

Suginami, H., D. M. Robertson and E. Diczfalusy (1978). Influence of the purity of the iodinated tracer on the specificity of the radioimmunoassay of human luteinizing hormone. Acta Endocrinol. (Kbh.) 89, 506-520

Suginami, H., Y. Koizumi and A. Nakajima (1981a). Measurements of human luteinizing hormone in plasma by in vitro bioassay and by conventional and improved radioimmunoassays. Endocrinol. Japon. 28, 87-94.

Suginami, H., M. Yano and A. Nakajima (1981b). A trial for the improvement of the in vitro bioassay for human luteinizing hormone. Endocrinol. Japon. 28, 95-100.

Suginami, H., Y. Koizumi, M. Yano and A. Nakajima (1982). Biological and immunological characterization of human luteinizing hormone discharged with a pulsatile fashion in normal menstrual cycle. Endocrinol. Japon. 29, 125-135.

Van Damme, M.-P., D. M. Robertson and E. Diczfalusy (1974). An improved in vitro bioassay method for measuring luteinizing hormone $(\mathrm{LH})$ activity using mouse Leydig cell preparations. Acta Endocrinol. (Kbh.) 77, 655-671.

Van Damme, M.-P., D. M. Robertson and E. Diczfalusy (1977). Biological and immunological characterization of human luteinizing hormone: III. Biological and immunological properties of urine preparations after electrofocusing. Mol. Cell. Endocrinol. 9, 69-79.

Wakabayashi, K. (1977). Heterogeneity of rat luteinizing hormone revealed by radioimmunoassay and electrofocusing studies. Endocrinol. Japon. 24, 473-485.

Yano, M., H. Suginami and A. Nakajima (1981). Quantitative and qualitative changes in human luteinizing hormone during continuous infusion of synthetic LH-RH in normal adult women (in Japanese). Folia Endocrinol. Japon. 57, 622 (Abstract).

Yen, S. S. C., O. Llerena, B. Little and O. H. Pearson (1968). Disappearance rates of endogenous luteinizing hormone and chorionic gonadotropin in man. J. Clin. Endocrinol. Metab. 28, 17631767.

Yen, S. S. C., R. Rebar, G. Vandenberg, F. Naftolin, Y. Ehara, S. Engblom, K. J. Ryan and K. Benirschke (1972). Synthetic luteinizing hormonereleasing factor: A potent stimulator of gonadotropin release in man. J. Clin. Endcrinol. Metab. 34, 1108-1111.

Zaidi, A. A., M. H. Qazi and E. Diczfalusy (1982). Molecular composition of human luteinizing hormone: Biological and immunological profiles of highly purified preparations following electrofocusing. J. Endocrinol. 94, 29-36. 